\title{
Diverging Awareness of Postoperative Delirium and Cognitive Dysfunction in German Health Care Providers
}

This article was published in the following Dove Press journal:

Clinical Interventions in Aging

\author{
H Sturm (D) \\ R Wildermuth (D) \\ R Stolz $\mathbb{D D}^{\prime}$ \\ L Bertram' \\ GW Eschweiler ${ }^{2}$ \\ C Thomas ${ }^{3}$ \\ $M$ Rapp $^{4}$ \\ $S$ Joos 1
}

'Institute for General Practice and Interprofessional Care, University Hospital Tübingen, Tübingen, Germany;

${ }^{2}$ Geriatric Center, University Hospital Tübingen, Tübingen 72076, Germany;

${ }^{3}$ Department of Old Age Psychiatry and Psychotherapy, Klinikum Stuttgart, Stuttgart, Germany; ${ }^{4}$ Department of Social and Preventive Medicine, University of Potsdam, Potsdam, Germany
Correspondence: $\mathrm{H}$ Sturm Institute for General Practice and Interprofessional Care, University

Hospital Tübingen, Osianderstr 5,

Tübingen 72076, Germany

$\mathrm{Tel}+4970712985269$

Fax +49 707I 295896

Email heidrun.sturm@med.uni-tuebingen.de
Purpose: Postoperative cognitive dysfunction (POCD) appears in up to $30 \%$ of patients suffering from postoperative delirium (POD). Both are associated with higher mortality and postoperative complications, prolonged hospital stays, and increased costs. Multi-modal models with pre-admission risk reduction counselling, perioperative monitoring, and training of multidisciplinary patient care providers have been shown to decrease the prevalence of both. The aim of our study is to understand how far those measures are known and implemented in routine care and to detect potential gaps in the current practice regarding risk communication and information flow between involved caregivers for patients at risk for POD/POCD.

Patients and Methods: As part of a multicenter study, seven semi-structured focus group (FG) discussions with nurses and physicians from tertiary care hospitals (surgery, anesthesiology, and orthopedics, $n=31$ ) and general practitioners (GPs) in private practice $(n=7)$ were performed. Transcribed discussions were analyzed using qualitative content analysis.

Results: POD is present above all in the daily work of nurses, whereas physicians do not perceive it as a relevant problem. Physicians report that no regular risk assessment or risk communication was performed prior to elective surgery. Information about POD often gets lost during hand-offs and is not regularly reported in discharge letters. Thus, persisting cognitive dysfunction is often missed. The importance of standardized documentation and continuous education concerning risks, screening, and treatment was emphasized. The oftensuggested pre-OP medication adjustment was seen as less important; in contrast, avoiding withdrawal was regarded as far more important.

Conclusion: Altogether, it seems that standards and available best practice concepts are rarely implemented. In contrast to physicians, nurses are highly aware of delirium and ask for standardized procedures and more responsibility. Therefore, raising awareness regarding risks, screening tools, and effective preventive measures for POD/POCD seems an urgent goal. Nurses should have a central role in coordination and care of POD to prevent the risk for POCD.

Keywords: cross-sectoral care, delirium prevention, postoperative cognitive dysfunction, POCD, dementia, clinical pathways, risk screening

\section{Introduction}

Postoperative delirium (POD) and cognitive dysfunction (POCD) are common in hospitalized elderly patients, especially in relation to general anesthesia. ${ }^{1,2}$ Their prevalence is likely to increase substantially with demographic change and advances in anesthesiology and intraoperative procedures, which lower the threshold for surgery in geriatric patients and even the very elderly. ${ }^{3}$ 
Delirium is a defined disease entity ${ }^{4}$ and can be described as "a clinical situation in which patients think and speak incoherently, are disoriented and show impairment of memory and attention" which is not explained by a medical history of dementia $\left[\ldots .{ }^{5}\right.$ POCD is less clearly defined as the pathogenic mechanisms are still unclear and diagnostic tests vary greatly. ${ }^{6}$ It can be described "as a range of changes in neurocognitive patients' condition and behaviors, for weeks or even months after anesthesia and operation". 5 About $12 \%$ of patients suffer from impaired cognitive capacities after surgery. ${ }^{4}$

Although POCD is less well described, it shares similar risk factors. ${ }^{7}$ Consequences of delirium include POCD, and both are associated with worse clinical outcomes (including increased length of hospital stays and long-term care utilization) and higher mortality. ${ }^{8-11}$ Also, long-term cognitive impairment and dementia can be triggered and aggravated. ${ }^{2,11,12}$ POCD, therefore, constitutes a significant burden to the healthcare system ${ }^{13,14}$ as well as to patients and families.

Evidence concerning risk factors is growing: next to pathophysiological factors like certain drugs, ${ }^{8}$ comorbid conditions, ${ }^{15}$ and anesthetic management, ${ }^{16-18}$ psychosocial factors such as age, multi-morbidity and frailty, low cognitive reserve, ${ }^{19}$ and preexisting dementia ${ }^{9}$ predispose patients to cognitive dysfunction and delirium in the context of hospitalization. Delirium itself is a risk factor for POCD. ${ }^{20}$

At the same time, there are effective procedures to decrease the risk of developing a delirium or shorten the duration by multidimensional, mostly nonpharmacological, interventions, which provide orientation and activation (eg, early mobilization) and continuity with contact persons. ${ }^{2,12,21}$ Preventing surgery- and anesthesia-induced cognitive dysfunction, avoiding polypharmacy, and securing adequate pain management are important medical procedures. ${ }^{22,23}$ Also, avoidance of certain drugs is recommended by clinical guidelines. ${ }^{8,24}$

In order to implement preventive or therapeutic procedures, patients at risk of delirium and cognitive dysfunction should be identified through screening on a regular basis, before but especially also after surgery to detect early signs of cognitive dysfunction. ${ }^{25}$ There are evaluated risk screening tools ${ }^{26}$ as well as delirium monitoring instruments ${ }^{27}$ available; however, up to now, they do not appear well integrated into clinical care processes. ${ }^{26,28-30}$

To understand hurdles for the broader implementation of improved care processes for these patients, we aim to clarify perceptions and concepts around POD/POCD management in Germany.

\section{Materials and Methods}

\section{Setting}

This qualitative study is part of a German multicenter trial in tertiary care hospitals, which aims to decrease the prevalence of POCD after elective surgery for patients over $75{ }^{26}$ Next to evaluating a multifaceted inpatient intervention and defining effective screening instruments, the goal of the part presented here is to describe how care providers of the entire process care for patients at risk of POD/POCD.

We performed five guided focus group discussions at two of five recruiting sites of the main study, aiming to include different professionals involved (physicians and nurses from the hospitals as well as referring specialists and general practitioners (GPs) (Table 1)).

\section{Data Collection}

A combination of purposive and snowball sampling was applied. ${ }^{31}$ Hospital staff were included by invitation of the study teams of the respective sites. Outpatient physicians sending patients to participating departments during the past year $(\mathrm{n}=130)$ were approached by letters or phone and also during several continuous medical education sessions.

As recruitment of outpatient physicians was difficult, the network of GP teaching practices of the Institute for General Practice and Interprofessional Care $(n=250)$ was approached, and we also included a phone interview with a GP from a teaching practice.

Focus group duration varied between 1:07 and 1:28 hrs. Focus groups were moderated by two researchers, with one individual participating in all discussions. Participants were informed about their right to withdraw at any time and about data handling and signed a written informed consent form. Discussions followed a structured guideline (see Table 1) but gave room to adjust discussions to upcoming topics. Information gained reached saturation after five $\mathrm{FG}$, and therefore, no additional FG were performed.

\section{Analysis}

Discussions and the interview were recorded and transcribed verbatim. The content was analyzed by means of structured content analysis ${ }^{32}$ using MaxQDA 2018.2 (VERBI) as a technical support system for qualitative data analysis.

The analysis was performed in steps. Categories were formed predominantly inductively, resulting in a complex category system with more than two hierarchical levels. All paraphrases were discussed with at least two of the 
Table I Focus Group/Interview Guideline

\begin{tabular}{|c|c|c|}
\hline & Main Question & Sub-Questions \\
\hline Introduction & $\begin{array}{l}\text { How relevant is } P O D / P O C D \text { in your daily routine? } \\
\text { What about risk screening for POD/POCD? } \\
\text { What about reviewing their medication in relation to POD/POCD? }\end{array}$ & $\begin{array}{l}\text { Do you perform it, which instruments, relevance? } \\
\text { (When) is it necessary? Is it feasible? Suggestions? }\end{array}$ \\
\hline \multirow[t]{4}{*}{ Key questions } & $\begin{array}{l}\text { Is there risk communication regarding POD/POCD prior to } \\
\text { deciding upon the surgery? }\end{array}$ & \\
\hline & $\begin{array}{l}\text { How is the exchange of information between hospital and referring } \\
\text { doctors organized with respect to risk factors of delirium and } \\
\text { POCD in geriatric patients prior to elective surgery? }\end{array}$ & $\begin{array}{l}\text {-What is the normal procedure? What are the path- } \\
\text { - Ways of information flow and how well does it work? } \\
\text { - Who is responsible for and participates in the care of } \\
\text { - What would be the ideal procedure - how does daily } \\
\text { routine differ from that? } \\
\text { - What information would you wish for? }\end{array}$ \\
\hline & $\begin{array}{l}\text { What kind of problems exist at the intersections between wards, } \\
\text { hospital, and outpatient care? }\end{array}$ & \\
\hline & $\begin{array}{l}\text { How does is the exchange of information function between } \\
\text { hospital and outpatient doctors? }\end{array}$ & Same questions for the process after selective surgery \\
\hline Final question & $\begin{array}{l}\text { Do you have any (further) ideas for improvement or any other } \\
\text { comments? }\end{array}$ & \\
\hline
\end{tabular}

following researchers (RW, HS, RS, LB), and consensus was always achieved by discussing grouping of the condensed paraphrases and building categories thereof. The information gained reached saturation, and therefore, no additional FG was performed.

\section{Results}

\section{Participants}

In total, seven GPs could be included and two hospital physicians, both of whom were still in training, both new to the surgical wards. Nurses and GPs were mostly very experienced professionals; GPs were either from teaching practices or, as in two cases, were recently retired. Hospital-based participants were from orthopedics, general surgery, or thoracic surgery (Table 2).

\section{Categories}

Three main categories were detected: (1) risk detection: perceived relevance, risk factors, and diagnostic tools; (2) prevention and therapy; and (3) information flow. The results follow roughly these categories. For subcategories, see Table 3.

The results are presented generally as per the three main categories mentioned but were also grouped logically when required.
Table 2 Focus Group Participants

\begin{tabular}{|l|l|l|l|}
\hline & GPs & $\begin{array}{l}\text { Hospital } \\
\text { Physicians }\end{array}$ & Nurses \\
\hline Total & $7^{\mathrm{a}}$ & 2 & 29 \\
\hline Female & $2(29 \%)$ & 0 & $25(86 \%)$ \\
ICU/intermediate care & & $\begin{array}{l}0 \\
2^{\mathrm{b}}\end{array}$ & 14 \\
\hline Surgical ward & & 44 \\
\hline
\end{tabular}

Notes: ${ }^{\text {a }}$ one of which was a phone interview. One nurse was also part of the study

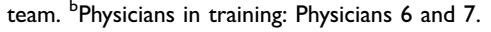

\section{Perceived Relevance of the Problem (Relevance)}

We found notably different perceptions between professionals concerning the prevalence of patients at delirium risk. GPs reported that they hardly ever saw patients who had experienced POD or POCD after surgery, whilst nurses (especially from ICU) reported that they were confronted with delirious patients at least daily. They felt that patients in an acute or subacute delirious state often go unnoticed by hospital physicians.

GP 2: [...] these cases are relatively singular/occasional. This occurs maybe twice a year. Or three times at most. Physician 1: I was just going to say, yes. Nurse 1: Oh dear, we have this, if we are lucky only twice a day. (laughter) [...]. (FG 1) 
Table 3 Summary of Categories of Structured Content Analysis

\begin{tabular}{|c|c|c|}
\hline & Relevance & Prevalence of Delirium \\
\hline & & $\begin{array}{l}\text { Consequences of delirium } \\
\text { Consequences of risk } \\
\text { screening }\end{array}$ \\
\hline & Risk factors ${ }^{a}$ & $\begin{array}{l}\text { Co-morbidities (diseases) } \\
\text { Substances } \\
\text { Medical procedures }\end{array}$ \\
\hline & $\begin{array}{l}\text { Responsibilities } \\
\text { Diagnostic tools }\end{array}$ & \\
\hline \multirow[t]{4}{*}{$\begin{array}{l}\text { Prevention and } \\
\text { therapy }\end{array}$} & $\begin{array}{l}\text { Verification of surgical } \\
\text { indication } \\
\text { Medication adjustment }\end{array}$ & \\
\hline & Patient information & $\begin{array}{l}\text { Responsibilities } \\
\text { Content } \\
\text { Media }\end{array}$ \\
\hline & Inpatient management ${ }^{\mathrm{a}}$ & $\begin{array}{l}\text { Dissatisfaction with status } \\
\text { quo } \\
\text { Responsibilities } \\
\text { Facilities and equipment } \\
\text { Personnel } \\
\text { Workflow } \\
\text { Relatives } \\
\text { How to deal with risks } \\
\text { (substances) } \\
\text { Other }\end{array}$ \\
\hline & Post-discharge & \\
\hline \multirow[t]{3}{*}{$\begin{array}{l}\text { Information } \\
\text { flow }^{b}\end{array}$} & Pre-hospital & \\
\hline & Inpatient & $\begin{array}{l}\text { Information, that is (not) } \\
\text { "arriving" } \\
\text { Information, that is } \\
\text { collected } \\
\text { Information, that is } \\
\text { transmitted }\end{array}$ \\
\hline & Post-discharge & \\
\hline
\end{tabular}

Notes: ${ }^{a}$ Not all categories are reported, as they are not relevant in the context of this paper. ${ }^{b}$ For the sake of readability, results of the category information flow were integrated into the other categories.

At the same time, nurses emphasize that these patients suffer and state that persisting cognitive deficits after delirium were common (although not called POCD).

Another aspect was the perceived lack of consequences or options.

Nurse 16: The question is, if this information was available beforehand, what could one, what could be changed afterwards, in the end regarding therapy? $[\ldots]$ if one has a good concept to prevent a delirium, then this of course is important, but we have that... I find it still a bit difficult [...]. (FG 3)

As GPs are not dealing with this problem frequently, they felt that their working knowledge was insufficient and identified a need for training.

GP 2: [...] and that CME of physicians is planned and also certain publicity is achieved. Well, I have to say, spontaneously I am not aware of delirium risk points at this moment. (FG 1)

However, it was emphasized that one was aware of measures to improve the care situation in the hospital (eg, supporting patient orientation on the ward and increasing activity of patients).

\section{Risk Assessment: Who, How, and When? (Risk Screening)}

If risk assessment had an impact on the care process, then GPs felt that they should be in charge. GPs felt that they should at least be involved in risk scoring, as they know the patient best. However, patients in Germany mostly are transferred to the hospital by specialists in outpatient practice. This was seen to contribute to the fact that little patientrelated information is received by the hospital staff.

Physician 2: [...] Actually, I always preferred to do the hospital transferral myself and not let the specialist do the transferral [...]. (FG 1)

Alternatively, it was suggested that the surgeons or anesthesiologists at the time of the patient's first visit to the hospital could also be responsible for risk screening, which could be done along with other risk factor assessments.

It was emphasized that there had to be enough time between informing the patient and admission (FG 3 , FG 2).

Physician 4: information needs to be given at a time, where the decision is made, whether they want to be operated in the first place (general agreement of the group) $[\ldots]$. (FG 2)

Often the risk is only detected after the surgery in the context of delirium screening (FG 1).

The need for structured screening tools or checklists also for GPs in the preoperative setting was raised at multiple FGs (FG 1, FG 2, FG 3). It was stated that both clear classification and structured documentation were missing. 
The nursing clinical documentation as well as that of GPs focused on physical, not on psychosocial, factors and free text made it difficult to systematically detect risk factors:

Nurse 26: $[\ldots]$ in the patient chart there are only empty spaces for psychosocial. I then write "seems stable" or "even-tempered" or "fearful" but that one can distinguish in detail, and that there are check-boxes for psychological topics $[\ldots]$ that one has asked: "are you frequently forgetful" or things like that for example [...]. (FG 5)

\section{Patient Information and Risk Communication Deciding About the Indication of an Elective Procedure/Surgery}

One simple way to avoid POD and POCD is not to operate. Some GPs stated that with elderly patients they were more reserved in recommending elective surgeries (FG 1), weighed against potential risks of a delay.

Physician 4: Yes, therefore it is even more necessary to reflect prior to elective procedures, do I do the surgery in the first place, do I recommend it to the patient? Or is it possible to fix it somehow differently. (FG 2)

However, recommending to avoid surgery might be difficult, as patients (and their relatives) do already have preexisting convictions, mostly based on the recommendation of the authority of specialists.

Physician 3: ...if the patient is already convinced of his new hip, it is difficult to tell him: listen, I'm not sure, if you really profit.... (FG 2)

It was pointed out that when patients are informed by surgeons about risks and benefits, risks tend to be less rigorously communicated (FG 1, 2, 3). As one contributing reason it was assumed that surgeons were exposed to economic interests and the pressure to keep patient numbers up.

Nurse 22: [...] would say, I do not recommend a surgery; they would all leave and go somewhere else afterwards [...] we loose those patients at some point and also the money, most likely also doctors have this in mind, implying, they would certainly not do a risk assessment deliberately, I think (approval in the room). (FG 5)

In addition, some participants wondered, what, if any consequences risk screening could have, given that the structures are not designed to react on it (FG 2 and 5).

\section{Risk Communication}

It was pointed out that patients (and their relatives) were often not informed of the risks of developing delirium and POCD sufficiently, the focus typically being the main diagnosis and surgical procedures (FG 2, 3, 4, 5).

Nurse 11: The physicians come to the patient, saying: as you know, you are here to get bypass surgery, thus, we take out veins of the leg [...] then you will stay for one night in intensive care. Do you have questions? This and this can happen. Seriously, this is how it goes. (FG 3)

Nurses suggested that patients would benefit from precise information about what to expect after surgery like the environment and physical state they will be in. They felt it would be helpful if nurses could be integrated into the informed-consent process or could walk patients and relatives through the wards and facilities. Also, videos showing the intensive care unit could be helpful but should not replace personal communication.

Nurse 11: [...] the patient does not expect to wake up with lines in his body, maybe being fixated to the bed.... (FG 3)

Nurse 16: [...] in a conversation regarding informed consent [...] the preference is that one does it together with the physician, since as a nurse, one translates a lot for the patient [...] The physician is in the clinic for the shortest moment, the most important one, since the surgery is performed, but the rest is much, much more important for the patient. (FG 3)

Delirium is associated with fears (FG 4: 24-24), and patients as well as their relatives at times try to hide cognitive deficiencies and sometimes even oppose cognitive screening (because they are ashamed). Therefore, it was repeatedly suggested by nurses and physicians that it would be helpful to have written information about the risks available at the GP (FG 1, 2, 3, 4).

\section{Medication Adjustment}

The main trial aims at adjusting medication prior to admission; however, it was necessary to first understand who would be responsible.

GPs felt offended and stated that if they could omit medication prior to surgery, this would imply that the medication would not be necessary in the first place (FG 1). Others pointed to the importance of recognizing the problem. There was a common thread in multiple FG that instead of omitting dangerous medication, it was important to prevent withdrawal by guaranteeing that certain medications are not stopped (FG 1, 3). In the inpatient 
situation, medication often gets adjusted to hospital standards. Information about stopped medication sometimes gets lost on the patient's pathway through different wards. Therefore, written medication plans reflecting outpatient medication were seen as crucial.

Physician 1: and your question I would turn into the opposite, for me or my patients it's not so much about: what can I leave out. That implies, that he gets something in vain. But rather about the question: is there a drug that needs to be continued under all circumstances. Thus, he should continue his benzodiazepine he takes for 20 years, since this [the withdrawal] makes real bad deliriums [...]. (FG 1)

Lack of knowledge concerning delirogenic medications was another factor mentioned. In the outpatient setting that could be alleviated by cooperation with pharmacists, the hospital "pharmaceutical rounds" might help (FG 4). Also, integrating delirogenic side effects of medication into the clinical software was a suggested solution, which could help GPs as well as anesthesiologists and all others (FG 1, 5).

\section{Delirium Management in the Hospital and Beyond}

There was a general dissatisfaction with the current situation: delirious, agitated patients need a lot of attention and manpower is often lacking. Patients may need to be sedated or constrained, which in turn triggers delirious states. Often the team only reacts when an agitated delirium has already occurred. Then, the focus is often more on drugs rather than on increasing activity or giving orientation. There was a consensus that delirium in the hospital is mainly registered and managed by nurses. Physicians often only pose "Yes-No Questions" which do not detect cognitive disorientation (FG 4) and hardly spend time with the patient. Therefore, it was felt that nurses would be best placed to take responsibility:

Nurse 16: ...I think, only we nurses can determine the care regiment for delirious patients as only we know, what kind of [symptoms] the patient experiences .... (FG 3)

Again, a structured delirium score was seen as helpful to communicate the diagnosis between professional groups.

The medication concept was judged as "non-convincing" and standardized protocols were missing (FG 2, 3). Nurses have little to no autonomy in the German system and doctors would not always trust their recommendations.
Nurse 8: And there is the personal attitude of the physician, who, concerning medication [...] that is difficult.

(FG 3)

The issue of lacking knowledge about POD and POCD was discussed with respect to bothnurses and physicians. In-house training and pocket guides for medication algorithms were suggested solutions (FG 2, 5).

Numerous issues concerning the ward organization and setup were raised by the care teams; all were dependent on available resources (eg, avoiding noise and light during the nighttime, giving additional orientation towards time and place, having an accessible contact person as a point of contact).

Again the wish for a structured policy across all departments was discussed with a view to prevention as well as treatment of acute delirious states. Currently, physicians usually act according to their intuitive judgement and experience. SOPs were not always implemented by physicians (FG 5) but well adhered to by nurses.

An integral delirium management policy was seen as an ideal framework.

Nurse 6: I think this would be cool, [...] in the sense of delirium-management. Say, the GP started to screen patients [...] he gets a red letter for admission [...] this would be transferred to the wards, they would have had trainings [...]. (FG 2)

\section{Information Flow}

The information reaching the hospital was perceived as (too) scarce, especially such information as a history of POD or risk factors. Information from the GP or referring physician to the hospital was usually unstructured and focused on the main diagnosis (but dependent on the awareness of the physician) and was complicated by not having a point of contact to whom to refer (FG 2, 3, 4, 5). To mitigate, it was suggested a proforma is used in the referral process. Such proformas are already implemented for ECG or other clinical data and should be completed with information about POD risk factors and medication.

Physician 4: $[\ldots]$ the patient gets information: [...] and bring the judgement of your GP concerning the POD risk score [...] just like an ECG or a bloodcount is asked for [...] the GP at least has "Aha, I have to think about, oh yes" [...]. (FG 2)

During the hospital stay, risks and episodes of cognitive dysfunction or POD are mostly documented by nurses and 
communicated to the physicians, eg, during rounds. During handovers, however, this information often gets lost despite documentation within nursing charts. Oral communication and the lack of structured delirium intensity documentation contribute to this information loss (FG 5). Compounding the problem was the issue of different IT-systems in different departments and between the different professions, where not all professionals can access all information (FG 1, 3, 4). As a solution, a flagged check-box (like for MRSA) or even a page with key information in the chart was suggested.

Information about an episode of POD during hospital stay gets communicated to the outpatient care providers either by nursing documentation if the patient is going to a nursing home or via the discharge letter. While communication to nursing homes was usually good, discharge letters reported deliriums (especially those without hyperactivity) less reliably. Information loss due to changing wards within the hospital was another factor (FG 1). Often relatives or home-care providers are late information sources for GPs (FG 1, 2).

Nurses raised the question, whether and how patients get cared for after having experienced a POD, as they would like to offer support to patients and relatives and inform them (FG 3). As GPs are often not informed or not aware of history of POD, there were no structured policies in use (FG 4).

GP 3: And in addition: oftentimes we do not detect deterioration of dementia [...] I am from a rural area, there relatives often do not realize, that the person after surgery is worse now. He still sits in the corner, not using his new TEP [...]. (FG 2)

Structured information and potentially "prescribing" activating exercises could help. The question was raised as to who could be involved in aftercare? Should it be physiotherapy, the relative, or other informal caregivers like young volunteer workers (FG 5)?

Nurse 25: actually, it needed something in the reimbursement catalogue that the GP can prescribe. Like activation or orientation, but that does not exist [...] And who should do that? I cannot make a prescription for the informal caregiver [...]. (FG 5)

\section{Suggested Improvement Measures}

Discussions of problems and solutions led to concrete suggestion on how to improve care organization for POD and POCD and are summarized in Table 4.

\section{Discussion}

This study intended to improve present care pathways of patients at risk for postoperative cognitive complications. We aimed to clarify perceptions of relevance, risk assessment, and communication of complications of POD in the German setting. As part of an ongoing interventional trial, these results are intended to serve as a basis for implementing effective measures to prevent and manage delirium and POCD in the everyday context.

\section{Varying Awareness and Knowledge}

The focus group discussions demonstrated clearly that awareness of POD/POCD differs vastly between professional groups, and cognitive impairment before and after surgery is not a frequently observed issue, especially in the primary care context. Also, hospital physicians do not consider the delirious patient to present frequently in their practice either. However, this is an everyday experience for nurses. In addition, there was little conviction about effective measures or consequences, neither in counseling about the indication nor in long-term support of POCD. The low awareness in surgeons regarding cognitive side effects of surgery is demonstrated by a recent press release of the German Surgical Society, stating that "endoprosthetic surgery should/could be recommended for patients above 80 , as it's known to help with related risks of myocardial infarction and pneumonia". ${ }^{33}$ Cognitive risks are not even mentioned. Low awareness also explains in retrospect our difficulties to recruit physicians for the focus groups; this was true for GPs as well as for both specialists in private practices, who refer their patients to the hospitals, and physicians (surgeons and anesthesiologists) in the hospital.

Although risk screening tests for POD exist, they are not widely used. ${ }^{4}$ Recent findings from the German GHoSt study (General Hospital Study), where the implementation of policies for the care of cognitively impaired patients in general hospitals was assessed, showed that standardized screenings or mandatory training were only implemented in a minority of wards. ${ }^{30}$ That cognitive risk is not sufficiently in focus was a major finding of our study. Cognitive risks are insufficiently discussed with patients prior to elective procedures which has an impact on the decision to undergo surgery and on the expectations concerning the time after the surgery. POD hinders adequate therapy after surgery and the hospital stay. A major result of our study was the recommendation to increase awareness in providers through training, flyers, and structured documentation tools. Furthermore, it was suggested 
Table 4 Improvement Measures

\begin{tabular}{|c|c|c|}
\hline Target & Setting & Measure \\
\hline $\begin{array}{l}\text { Awareness/ } \\
\text { knowledge }\end{array}$ & & $\begin{array}{l}\text { - More CME or trainings } \\
\text { - Written information, leaflets for professionals and patients } \\
\text { - Checklists within clinical/practice information systems } \\
\text { - Standards (SOPs, patient pathways) } \\
\text { - Knowledge about effective POCD therapy/post-discharge support needed }\end{array}$ \\
\hline \multirow[t]{3}{*}{ Communication } & Pre-hospital & $\begin{array}{l}\text { - Proformas from hospital to referring physician } \\
\text { - Electronic medication plan }\end{array}$ \\
\hline & Within hospital & $\begin{array}{l}\text { - Check-box for history of delirium } \\
\text { - Standardized screening and delirium severity documentation (proforma) } \\
\text { - Information about delirium (also from nurses) needs to be accessible for all involved providers. }\end{array}$ \\
\hline & Trans-sectoral & $\begin{array}{l}\text { - Delirium passport, which remains with the patient } \\
\text { - Inclusion of nurses' documentation in discharge letters } \\
\text { - Electronic medication plan/electronic patient chart }\end{array}$ \\
\hline \multirow[t]{3}{*}{ Care process } & Pre-hospital & $\begin{array}{l}\text { - Standards for (risk) screening tests } \\
\text { - Clear responsibilities for risk counseling and communication }\end{array}$ \\
\hline & Within hospital & $\begin{array}{l}\text { - Inappropriate medication alerts in CIS } \\
\text { - Including pharmacists/geriatricians } \\
\text { - More therapeutic responsibilities for nurses } \\
\text { - More personnel, including relatives and informal caregivers } \\
\text { - Better infrastructure to adjust the organizational process to the needs of delirious patients }\end{array}$ \\
\hline & Trans-sectoral & $\begin{array}{l}\text { - Trans-sectoral policy including GPs, referring physicians and family } \\
\text { - Policies concerning support after POD (eg, physiotherapy, activating home visits by volunteers, etc) }\end{array}$ \\
\hline
\end{tabular}

Abbreviation: CIS, clinical information system.

that offering site visits to patients and enabling participation of nurses in the preparatory process would be helpful. Also, anesthesiologists, who are often responsible for perioperative management and the communication to the patient regarding the risk of postoperative complications beyond the surgery, could be more formally involved in the screening process.

\section{Awareness on the Rise?}

To be able to act, awareness and knowledge are prerequisites. The numbers of publications dealing with POD/ POCD in the German scientific community ${ }^{2,19,23,34,35}$ as well as in the lay press ${ }^{36}$ seem to be increasing, thus improving wider awareness. The problem and treatment options for POD are well described in the literature; POD (not POCD) guidelines exist in many countries. ${ }^{28,37}$

However, there still appears to be a knowledge gap in Germany. ${ }^{38}$ Despite available German risk screening tools, ${ }^{23}$ physicians in our focus groups felt unsure as to what is available or standard in the care of patients at risk of delirium or POCD. In addition, many risk factors cannot be avoided. ${ }^{39}$ A lack of knowledge concerning assessment tools as well as a lack of policies for managing these patients was found in other countries too, eg, Sweden. ${ }^{40}$ Also, specific treatment options for POCD are lacking ${ }^{4}$ even though prevention of POD seems crucial for the long-term cognitive outcome, and similar to POD prevention, activating therapy seems to alleviate cognitive function. ${ }^{2}$ Accordingly, one of the aims of the PAWEL-consortium was to establish an appropriate delirium risk screening tool. ${ }^{26}$

\section{Missing Implementation of (Comprehensive) Concepts}

Existing guidelines mostly focus on the clinical setting and therefore on screening and therapy after surgery or in an intensive care setting. ${ }^{7,40-43}$ A holistic and trans-sectoral perspective, especially for geriatric patients, seems to be missing. ${ }^{10}$ Consequently, recommendations concerning delirium risk assessment as an indispensable part of the joint decision-making process for an elective procedure are usually missing too. Effective (risk) communication, however, is an ethical requirement of each patient-physician relationship, and deficits could even imply legal 
consequences. ${ }^{44}$ GPs also should have a crucial role in "prehabilitation": frailty, preexisting cognitive impairment, malnutrition, and potentially inappropriate medication are defined as risk factors, some of which can be adjusted prior to hospitalisation. ${ }^{23}$ Based on this, the initial goal of our study consortium was to implement pre-admission medication. However, our results showed that this is neither perceived as helpful nor implementable in the present organization flow. As a learning point, this demonstrates how important it is to consider professionals' perceptions prior to adjusting care. ${ }^{45}$

In addition, guidelines do not address responsibilities for risk detection and risk communication. This raises the problem of the implementation gap. In the German-speaking community, increasing teaching about POD/POCD is recommended in order to increase awareness. ${ }^{46}$ The German Alzheimer Society looked at reasons for the lack of uptake of dementia-friendly hospitals which have proven beneficial effects. In addition to economic constraints, the focus is typically on physical diagnoses and neglect social and other patient needs. ${ }^{47}$ This is supported by our findings, where the perceived authority of specialists (along with societal attitudes towards "quick-fixes") was blamed for not comprising or altering decisions on therapeutic measures. Nurses in our study also sometimes felt unheard, which is a known problem in German hospitals and is partly explained by the (hierarchical) hospital culture. ${ }^{48}$

Physicians and nurses in our focus groups suggested that written information about either screening tools or therapeutic options would be useful in the practice setting, as would pre-structured delirium (risk) documentation (proformas) in the hospital. This indicates that information also needs to be tailored to the workflow in order to be taken up. ${ }^{49}$

\section{Difficulties in Information Flow}

Ideally, there should be a common understanding of all involved providers of how risk is assessed and who is responsible for screening, how delirium is treated, and how information about it is passed on to the next stage of care. This goal is far from being achieved as the difficulties in information flow detected here show: information about pre-existing risks or cognitive impairment only rarely reaches the hospital staff before the operation. Also, within the hospital, information gets lost, and therefore also after hospitalization, oftentimes the GP does not learn about cognitive incidents during the hospital stay. German data indicate, that only half of the patients get a proper medical diagnosis of dementia, ${ }^{23}$ and therefore, pre-existing dementia is only known to the staff in about $40 \%$ of the cases ${ }^{15}$ and that, of course, makes preventive measures difficult. ${ }^{50}$

\section{Limitations}

We only had limited access to physicians, especially surgeons or anesthesiologists. However, the views of the participants were congruent. Although international literature points to similar issues, this study is strongly related to the local German setting. Also, we assumed that in other hospitals the situation should not differ significantly, but still the results are restricted to two tertiary care hospitals.

\section{Conclusion}

While nurses consider delirium and related problems highly relevant, there appears to be limited awareness of the conditions amongst physicians. This hampers risk assessment, screening, and prevention of POD/POCD. Despite existing evidence-based screening tools as well as prevention and treatment options, standardized transsectoral policies are scarce and often not implemented; referring doctors and GPs responsible for follow-up care are frequently excluded. Nurses could have a bigger role in managing these patients. Also, documentation and communication would benefit from being standardized. Despite these findings, it seems that overall awareness is increasing. Future research should focus on the implementation of effective preventive interventions.

\section{Abbreviations}

POD, post-operative delirium; POCD, post-operative cognitive dysfunction; FG, focus group; GP, general practitioner; CIS, clinical information system.

\section{Ethics Approval and Clinical Trial Register Details}

The PAWEL study was approved by the Ethics Commission of the Faculty of Medicine of the Eberhard-Karls University and University Hospital Tübingen with number 517/ 2017BO1 on the 12 October 2017 (amendment for focus groups on 17 May 2018) and by the Ethics Commission of the University of Potsdam with number 38/2017 on the 11 December 2017. PAWEL was registered on the German Clinical Trials Register (number DRKS00013311; https:// www.drks.de/drks web/navigate.do?navigationId=trial. HTML\&TRIAL_ID=DRKS00013311) on 10 November 2017. 


\section{Acknowledgments}

We thank all participants of the focus groups as well as the PAWEL Consortium for the organizational support. This study is funded by the Innovationfonds 01VSF16016 (PAWEL).

\section{Author Contributions}

HS, RW, and SJ designed this study. RW, LB, HS, and RS conducted focus groups and performed and discussed structured content analysis. GE, CT, and SJ supported participant acquisition for the focus groups. HS drafted the manuscript supported by RW. All authors contributed to and approved the final draft, contributed to data analysis and drafting or revising the article, gave final approval of the version to be published, and agreed to be accountable for all aspects of the work.

\section{Funding}

This study is funded by the Innovationsfonds (Fund of the Federal Joint Committee, Gemeinsame Bundesausschuss, G-BA), who had no role in the design of the study, and did not have any role during its execution, or in the analyses of the data, or in the decision to submit any results.

\section{Disclosure}

Mrs L Bertram reports grants from Innovationfonds outside the submitted work. Prof. Dr. G Eschweiler reports grants from Innovationsfonds PAWEL, during the conduct of the study. Dr C Thomas reports grants from Innovation fund G-BA, during the conduct of the study. Prof. Dr. M Rapp reports grants from BMBF during the conduct of the study and personal fees from Willmar Schwabe $\mathrm{GmbH}$ outside the submitted work. The authors report no other conflicts of interest in this work.

\section{References}

1. O'Brien H, Mohan H, Hare CO, Reynolds JV, Kenny RA. Mind over matter? The hidden epidemic of cognitive dysfunction in the older surgical patient. Ann Surg. 2017;265(4):677-691. doi:10.1097/ SLA.0000000000001900

2. Zoremba N, Coburn M. Acute confusional states in hospital. Deutsches Ärzteblatt. 2019;116(7):101-106.

3. Augurzky B, Hentschker C, Pilny A, Wübker A Krankenhausreport 2017 [Hospital Report 2017]. Siegburg; 2017.

4. Needham MJ, Webb CE, Bryden DC. Postoperative cognitive dysfunction and dementia: what we need to know and do. $\mathrm{Br} J$ Anaesth. 2017;119(suppl_1):i115-i125. doi:10.1093/bja/aex354

5. Pappa M, Theodosiadis N, Tsounis A, Sarafis P. Pathogenesis and treatment of post-operative cognitive dysfunction. Electronic Phys. 2017;9(2):3768-3775. doi:10.19082/3768
6. Krenk L, Kehlet H, Baek Hansen T, Solgaard S, Soballe K, Rasmussen LS. Cognitive dysfunction after fast-track hip and knee replacement. Anesth Analg. 2014;118(5):1034-1040. doi:10.1213/ ANE.0000000000000194

7. Kotekar N, Shenkar A, Nagaraj R. Postoperative cognitive dysfunctioncurrent preventive strategies. Clin Interv Aging. 2018;13:2267-2273. doi:CIA.S230800/CIA.S133896

8. Inouye SK, Westendorp RG, Saczynski JS. Delirium in elderly people. Lancet (London, England). 2014;383(9920):911-922. doi:10.1016/ S0140-6736(13)60688-1

9. Robinson TN, Raeburn CD, Tran ZV, Angles EM, Brenner LA, Moss M. Postoperative delirium in the elderly: risk factors and outcomes. Ann Surg. 2009;249(1):173-178. doi:10.1097/SLA.0b013e31818e4776

10. Johansson YA, Bergh I, Ericsson I, Sarenmalm EK. Delirium in older hospitalized patients-signs and actions: a retrospective patient record review. BMC Geriatr. 2018;18(1):43. doi:10.1186/s12877-018-0731-5

11. Witlox J, Eurelings LS, de Jonghe JF, Kalisvaart KJ, Eikelenboom P, van Gool WA. Delirium in elderly patients and the risk of postdischarge mortality, institutionalization, and dementia: a meta-analysis. JAMA. 2010;304(4):443-451. doi:10.1001/jama.2010.1013

12. Muller A, Lachmann G, Wolf A, Morgeli R, Weiss B, Spies C. Peri- and postoperative cognitive and consecutive functional problems of elderly patients. Curr Opin Crit Care. 2016;22(4):406-411. doi:10.1097/MCC. 0000000000000327

13. Deiner S, Silverstein JH. Postoperative delirium and cognitive dysfunction. Br J Anaesth. 2009;103(Suppl 1):i41-46. doi:10.1093/ bja/aep291

14. Rudolph JL, Marcantonio ER, Culley DJ, et al. Delirium is associated with early postoperative cognitive dysfunction. Anaesthesia. 2008;63 (9):941-947. doi:10.1111/j.1365-2044.2008.05523.x

15. Bickel H, Hendlmeier I, Heßler JB, et al. The prevalence of dementia and cognitive impairment in hospitals. Dtsch Arztebl Int. 2018;115 (44):733-740.

16. Vlisides P, Avidan M. Recent advances in preventing and managing postoperative delirium [version 1; peer review: 2 approved]. F1000Research. 2019;8(607).

17. Devlin JW, Skrobik Y, Gelinas C, et al. Clinical practice guidelines for the prevention and management of pain, agitation/ sedation,delirium, immobility, and sleep disruption in adult patients in the ICU. Crit Care Med. 2018;46(9):e825-e873.

18. Chan MT, Cheng BC, Lee TM, Gin T, Group CT. BIS-guided anesthesia decreases postoperative delirium and cognitive decline. $J$ Neurosurg Anesthesiol. 2013;25(1):33-42. doi:10.1097/ANA.0b01 $3 \mathrm{e} 3182712 \mathrm{fba}$

19. Feinkohl I, Winterer G, Spies CD, Pischon T. Cognitive reserve and the risk of postoperative cognitive dysfunction. Dtsch Arztebl Int. 2017;114(7):110-117. doi:10.3238/arztebl.2017.0110

20. Kratz T, Diefenbacher A. Delirium as a risk factor for POCD. Dtsch Arztebl Int. 2017;114(20):362.

21. Reston JT, Schoelles KM. In-facility delirium prevention programs as a patient safety strategy: a systematic review. Ann Intern Med. 2013;158 (5 Pt 2):375-380. doi:10.7326/0003-4819-158-5-201303051-00003

22. Kotekar N, Kuruvilla CS, Murthy V. Post-operative cognitive dysfunction in the elderly: a prospective clinical study. Indian J Anaesth. 2014;58(3):263-268. doi:10.4103/0019-5049.135034

23. Olotu C, Weimann A, Bahrs C, Schwenk W, Scherer M, Kiefmann R. The perioperative care of older patients. Dtsch Arztebl Int. 2019;116 (5):63-69. doi:10.3238/arztebl.2019.0063

24. Inouye SK, Marcantonio ER, Metzger ED. Doing damage in delirium: the hazards of antipsychotic treatment in elderly persons. Lancet Psychiatry. 2014;1(4):312-315. doi:10.1016/S2215-0366(14) 70263-9

25. American Geriatrics Society Expert Panel on Postoperative Delirium in Older A. American Geriatrics Society abstracted clinical practice guideline for postoperative delirium in older adults. $J$ Am Geriatr Soc. 2015;63(1):142-150. doi:10.1111/jgs.13281 
26. Sanchez A, Thomas C, Deeken F, et al. Patient safety, cost-effectiveness, and quality of life: reduction of delirium risk and postoperative cognitive dysfunction after elective procedures in older adults-study protocol for a stepped-wedge cluster randomized trial (PAWEL Study). Trials. 2019;20(1):71. doi:10.1186/s13063-018-3148-8

27. Barr J, Fraser GL, Puntillo K, et al. Clinical practice guidelines for the management of pain, agitation, and delirium in adult patients in the intensive care unit. Crit Care Med. 2013;41(1):263-306. doi:10.1097/CCM.0b013e3182783b72

28. American Geriatrics Society Expert Panel on Postoperative Delirium in Older A. Postoperative delirium in older adults: best practice statement from the American Geriatrics Society. J Am Coll Surg. 2015;220(2):136-148 e131. doi:10.1016/j.jamcollsurg.2014.10.019

29. Grifasi C, Calogero A, Esposito A, Dodaro C. Perioperative care of elderly outpatients. A review. Ann Ital Chir. 2015;86(2):100-105.

30. Hendlmeier I, Bickel H, Hessler JB, et al. Demenzsensible Versorgungsangebote im Allgemeinkrankenhaus: reprasentative Ergebnisse aus der General Hospital Study (GHoSt) [Dementia friendly care services in general hospitals: representative results of the general hospital study (GHoSt)]. Z Gerontol Geriatr. 2018;51 (5):509-516. doi:10.1007/s00391-017-1339-7

31. Moser A, Korstjens I. Series: practical guidance to qualitative research. Part 3: sampling, data collection and analysis. Eur J Gen Pract. 2018;24(1):9-18. doi:10.1080/13814788.2017.1375091

32. Schreier M. Qualitative Content Analysis in Practice. Los Angeles (UA): SAGE; 2012.

33. dpa/ths. Operationen bei 80 -Jährigen nicht mehr so risikoreich [Surgery less risky in 80-year-olds]. Ärzte Zeitung online. 2019.

34. Kratz T, Heinrich M, Schlauß E, Diefenbacher A. The preventing of postoperative delirium. Dtsch Arztebl Int. 2015;112(17):289-296. doi:10.3238/arztebl.2015.0289

35. Bringemeier J, Thomas C, Guhra M, Kreisel S. HELP zur Vermeidung von Delirien. Lege Artis. 2015;5(04):137-148.

36. Spiewack M OP gelungen, Patient verwirrt - Im Krankenhaus droht Älteren ein Trauma, das sie nie wieder loswerden. Was tun gegen die Desorientierung? [Successful surgery but confused patient - in the hospital elderly face a trauma, they never get rid off. What to do against the desorientation?]. Die Zeit. 2016.

37. NICE. Delirium: prevention, diagnosis and management. Clinical guideline [CG103]; Published July 2010; Updated March 2019. Available from: https://www.nice.org.uk/guidance/cg103. Accessed 30 November 2019

38. Kirchen-Peters S. Schwerpunkt: die Versorgung der Pflegebedürftigen [Focus: care of persons in need of care]. In: Jacobs K, Kuhlmey A, Greß S, Klauber J, Schwinger A, Bade Verdugo P, editors. [PflegeReport 2017]. Stuttgart: Schattauer; 2017:153ff. German.

39. Langer T, Santini A, Zadek F, et al. Intraoperative hypotension is not associated with postoperative cognitive dysfunction in elderly patients undergoing general anesthesia for surgery: results of a randomized controlled pilot trial. J Clin Anesth. 2019;52:111-118. doi:10.1016/j. jclinane.2018.09.021
40. Jildenstal PK, Rawal N, Hallen JL, Berggren L, Jakobsson JG. Perioperative management in order to minimise postoperative delirium and postoperative cognitive dysfunction: results from a Swedish web-based survey. Ann Med Surg (2012). 2014;3(3):100-107. doi:10.1016/j.amsu.2014.07.001

41. Feinkohl I, Winterer G, Pischon T. Associations of dyslipidaemia and lipid-lowering treatment with risk of postoperative cognitive dysfunction: a systematic review and meta-analysis. J Epidemiol Community Health. 2018.

42. Liu X, Yu Y, Zhu S. Inflammatory markers in postoperative delirium (POD) and cognitive dysfunction (POCD): a meta-analysis of observational studies. PLoS ONE. 2018;13(4):e0195659. doi:10.1371/journal.pone.0195659

43. (DGAI) Gsoaaic, (DIVI) Giafi-aem. S3-Leitlinie 001/012: analgesie, Sedierung und Delirmanagement in der Intensivmedizin [S3-guideline: analgesy, sedation and delirium management in intensive care]. AWMF online.Register Nummer 001/012; 2015.

44. Setacci C, Sirignano A, Ricci G, Spagnolo AG, Pugliese F, Speziale F. A new ethical and medico-legal issue: vascular surgery and the postoperative cognitive dysfunction. J Cardiovasc Surg (Torino). 2015;56(4):607-615.

45. Campbell M, Fitzpatrick R, Haines A, et al. Framework for design and evaluation of complex interventions to improve health. BMJ. 2000;321(7262):694-696. doi:10.1136/bmj.321.7262.694

46. Meyjohann B, Leischker SR, Thomas C. Multiprofessioneller Standard zur Delirprophylaxe und -behandlung [Mulitprofessional standard for prophylaxis and therapy of delirium]. Alterstraumatologie Kongress 2016. Marburg; 2016.

47. Kirchen-Peters S, Herz-Silvestrini D Herausforderung Demenz im Krankenhaus. Ergebnisse und Lösungsansätze aus dem Projekt Dem-i-K [Challenge dementia in the hospital. Results and Solutions from the project Dem-i-K]. Saarbrücken2013.

48. Wagner A, Hammer A, Manser T, Martus P, Sturm H, Rieger MA. Do occupational and patient safety culture in hospitals share predictors in the field of psychosocial working conditions? Findings from a cross-sectional study in German University Hospitals. Int J Environ Res Public Health. 2018;15:10. doi:10.3390/ijerph15061188

49. Wensing M, Bosch M, Grol R. Determinants of change. In: Grol R, Wensing M, Eccles M, Davis D, editors Improving Patient Care: The Implementation of Change in Health Care, 2nd Edition. Hoboken: John Wiley and Sons; 2013:139-150.

50. Kirchen-Peters S. Menschen mit Demenz im Akutkrankenhaus: von der Diskrepanz zwischen innovativen Ansätzen und Versorgungsrealität [Persons with dementia in the hospital: about the discrepancy between innovative care approaches and reality]. In: Jacobs K, Kuhlmey A, Greß S, Klauber J, Schwinger A, Bade Verdugo P, editors. PflegeReport 2017. Stuttgart: Schattauer; 2017:325.
Clinical Interventions in Aging

\section{Publish your work in this journal}

Clinical Interventions in Aging is an international, peer-reviewed journal focusing on evidence-based reports on the value or lack thereof of treatments intended to prevent or delay the onset of maladaptive correlates of aging in human beings. This journal is indexed on PubMed Central, MedLine, CAS, Scopus and the Elsevie
Bibliographic databases. The manuscript management system is completely online and includes a very quick and fair peer-review system, which is all easy to use. Visit http://www.dovepress.com/ testimonials.php to read real quotes from published authors. 